\title{
MATHEMATICS FOR PHYSICISTS AND ENGINEERS
}

\begin{abstract}
$M$ ATHEMATICS FOR PHYSICISTS AND EN$G I N E E R S$ is the fourth of the Organization for Economic Co-operation and Development's New Thinking series*. Its predecessor dealt with school mathematics, expressing some wildly revolutionary proposals. The present report is by comparison mild.

For the engineer and physicist, mathematics must be concrete at all levels, the syllabus must be motivated by technical relevance, exercises should be drawn from real-life applications, and, if necessary, breadth of coverage must yield to depth of understanding. Topies in modern mathematics will find a place as soon as their technical applications prove important; as for logical rigour, the truth must be told, but perhaps not the whole truth. To achieve these objectives, there must be much greater co-ordination between mathematical, scientific and engineering teachers at all levels. "If the teacher is a mathematician, he must know something about the problems

* Organization for Economic Co-operation and Development. Mathematies for Physicists and Engineers: Report of the O.E.E.C. Seminar on "The Mathematical Knowledge required by the Physicist and the Hngineer", Chateau de la Muette, Paris, February 1961 . (Project STP 17.) 'Pp. 223. (Paris: Organization for Economic Co-operation and Development, 1961.) n.p.
\end{abstract}

and methods of the physicist and engineer, and vice versa."

So much is common ground; it is in the mode of implementing these suggestions that the report exhibits a variety of opinions. If new topics are to go in, must old and valued material go out, or can room be found by using improved teaching methods ? How far up the school or university can a common course in mathematics be taken ? Should the elemen. tary topics be taught by the mathematician and the advanced subjects by the scientist, or vice versa? Is it true that the spirit of contemporary abstract mathematics "no longer coneerns only those who used to be called geometers . . . but concerns in fact the whole scientific community" ? Will engineers thrive on Bourbaki?

The papers and discussions are full of valuable information on conditions in Europe and North America, and on experiments that are being made; they also contain speculations and suggestions about what the teacher of to-morrow may need to know and to do. So far as Britain is concerned, it seems that the technical mathematical teaching is kept close to physical reality, but is slow in making use of advanced methods and techniques in pure mathematics.

\section{MALARIA EPIDEMIC IN MAURITIUS}

$\mathrm{M}$ ALARIA was hyperendemic in Mauritius until a large-scale control programme was started in 1949. The programme was based on a general attack by residual insecticide (DDT) and was conspicuously successful within a short time. By 1953 malaria-rates were reduced to a negligible level and the principal vector, Anopheles funestus, was eradicated. Total coverage spraying was then abandoned, and, until 1960 , antimalaria measures consisted only of a limited programme of case-finding and parasite surveys, which did not come up to the standards now universally accepted for surveillance operations in malaria programmes.

In 1959, the Government of Mauritius and the World Health Organization agreed on a plan for the complete eradication of malaria from the island. Under this plan, full-scale surveillance operations were started in a small district in March of that year, chiefly for training purposes, and a surprisingly high number of fresh cases of malaria was detected. Because of this alarming situation, active case detection was rapidly extended over the whole island, and, as a result, 1,001 cases were found during the period April-June. The majority of the cases occurred in limited areas with an over-all total of about 70,000 inhabitants, the incidence of malaria being approxim. ately $14 \cdot 2$ per 1,000 , which, in an area where malaria had been practically eradicated, had to be considered as an epidemic.

It is possible that a low degree of malaria transmission had been going on continuously since the withdrawal of total coverage spraying in 1953, and that a parasite reservoir-previously undetected owing to the limited degree of surveillance-was slowly building up until, by spring 1960 , it had reached a sufficiently high level to start an epidemic. Although respraying of the foci.was undertaken in an attempt to remedy the situation, it became obvious in 1961 that this measure was inadequate. In the first three quarters of $1961,190,702$ and 83 cases of malaria were detected, mainly in areas adjacent to the foci treated in 1960 . This has necessitated reverting to the attack phase in areas with a population of more than 200,000 .

The work being carried rut by the Government of Mauritius and the World Health Organization to combat these epidemics is reported in a recent issue of the WHO Chronicle (16, No. 2; February 1962).

\section{ATTENUATED MEASLES VACCINE}

$\mathrm{D}$ R. HUANG-CHEN-HSIANG, Chia Ping-yi, Chu Fu-T'ang, Kuo Ke-Ch'ien, Wang Hui-Ying, Wu Tsung-Lin and Wu Hsueh-Hsin have examined the clinical reactions of an attenuated measles virus of vaccine $L_{4}$ (37 passages in human amnion cells). They were considerably milder than those of vaccine
$M_{60-5}$ (5 passages in human amnion cells). The difference was chiefly limited to catarrhal symptoms and signs, rash and Filatov-Koplik's spots. There was, however, no appreciable difference if the average intensity and duration of fever were compared. Dr. Huang-Chen-Hsiang et al. report their findings in the 